\title{
AN EXPLORATORY STUDY OF THE USAGE OF BANNED SOCIAL NETWORKING SITE 'REDDIT’ IN INDONESIA
}

\author{
Martin James Moloney, Hanifah Mutiara Sylva \\ Bina Nusantara University, Jakarta. \\ mmoloney@binus.edu
}

Diajukan: 09-09-2019; Direview: 09-11-2019; Diterima: 16-12-2019;

\begin{abstract}
:
Reddit is a news aggregation website that uses user-sourced content to appeal to and incite interaction(s) with other 'Redditors' (Reddit users or contributors) within sometimes niche and often more generalized subjects. It is primarily a news aggregation website that acts as a forum for interested parties to join in discussion and contribute their own material relating to various topics. A voting process known as upvoting and downvoting moderates the posts and comments and dictates their popularity and exposure. Majority of its users to adopt virtual private networks (VPNs). Through mixed methods research, researcher seeks if its users directed abuse towards their own country, or people or revealed hidden interests in deviancy, sedition or dissent on the forum. The researchers studied the 200 most popular posts of all time on the $\mathrm{r} /$ Indonesia subreddit in February 2019. These were ranked by Reddit according to the number of upvotes/downvotes from readers of the forum. This research finds that the Indonesia sub-forum is not a concern to the country's government and if anything the contributors are a benign meeting of oft-humorous, worldly and welcoming minds.
\end{abstract}

Keywords: social media, Reddit, Indonesia, ban, censorship

\section{INTRODUCTION}

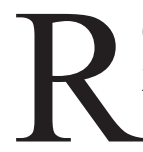

eddit.com is a website that was founded in 2005 by University of Virginia room-mates Steve Huffman and Alexis Ohanian. It was sold in 2006 to Condé Nast Publications, and as Greenberg (2015) states, “[now] Condé Nast's parent company, Advance Publications, is Reddit's majority shareholder". According to Nicol (2018), "Reddit is the fifth most popular site in the United States, and the 18th [most popular] worldwide". Reddit describes itself as 'the front page of the internet'. It is primarily a news aggregation website that acts as a forum for interested parties to join in discussion and contribute their own material relating to various topics. For this reason of userparticipation, it is considered part of the 'Web 2.0' iteration that leverages social interaction to create value in a forum or website.

The site is divided into different sections, known as 'subreddits', based on the interests of each group. Each sub-reddit is prefixed with an ' $r$ '' to denote that it is a subsection of the main site. The following table shows the most popular subreddits on the site:

Table 1. Most Popular Subreddits (Mar 1, 2019)

\begin{tabular}{lll}
\hline 1 & /r/announcements & $21,352,277$ \\
\hline 2 & /r/funny & $18,974,028$ \\
\hline 3 & /r/AskReddit & $18,752,990$ \\
\hline 4 & $/$ r/todayilearned & $18,434,007$ \\
\hline 5 & $/$ r/science & $18,321,396$ \\
\hline 6 & /r/worldnews & $18,310,545$ \\
\hline 7 & /r/pics & $18,259,401$ \\
\hline 8 & $/$ r/IAmA & $17,745,577$ \\
\hline 9 & /r/gaming & $17,696,844$ \\
\hline 10 & /r/videos & $17,424,011$ \\
\hline
\end{tabular}

Source: redditmetrics.com

The popularity of individual posts on subreddits is determined via a system of 'upvotes' and 'downvotes' by the users themselves, or 'Redditors' as they are commonly known. An upvote is essentially a recommendation, or 'like', while a downvote is a condemnation or 'thumbs-down' for a post. Comments on posts from other users (or the OP, or original poster) are also subject to the 
same upvoting and downvoting system. It is overly simplistic to suggest that this is a comprehensive overview of how the Reddit algorithm works, as it remains proprietary and not fully explained to its users.

Some subreddits have attracted media attention for featuring content which has pushed the envelope of free speech and/or good taste. Subreddits such as ' $r$ /jailbait' and ' $r$ /creepshots' were both shut down after an outcry, both online and in traditional, mainstream media (Nguyen, 2011). The jailbait sub-reddit featured images of adolescent females, while r/creepshots displayed "suggestive photos of women taken in public" without their permission (Alfonso, 2012).

Many of the subreddits have controversial or risqué material, and some are deemed 'pornographic' enough to have caused the entire Reddit site to be banned in Indonesia by ISPs compliant to the government's demands (Stainkampf, 2016). The researcher's ability to reach Reddit was unimpeded, however, due to ISP differences which meant that the researcher could access a site that was ostensibly blocked for the majority of its Indonesian users.

The biggest subreddit dedicated to Indonesian interests is $\mathrm{r} /$ Indonesia. At the time of writing it had 35,904 subscribers; this is a relatively small community for a subreddit. The government ban in May 2014 (Lukman, 2014) had little to no effect on the viewership figures on the website. If anything, the ban served to galvanize users to access the site by whatever means they could; according to Google Trends (2018) the ban did not affect the upwardly rising trend which continued until the time of writing.

With the majority of ISPs blocking the site, Indonesian users have had to resort to using virtual private networks (VPNs) that mask the internet protocol (IP) address of the computer (a computer's geographically-linked unique number), making it appear to originate outside of Indonesian territories. Indonesia is the country with the largest VPN usage in the world. According to Nave (2016), 41\% of Indonesians shield their presence online by using VPNs to "overcome governmental restrictions".

According to Mason (2018), "the Indonesian government is yet to make the use of VPNs illegal". This, however, begs the question, if Indonesians are prepared to disregard the blocking of a proscribed website and access it through a legal loophole, are they also going to engage in discussing issues that are contrary to their country's social norms or the government's interests? Worse, from the government's perspective, would they take to anti-Indonesian values and espouse values that are outside of their normative environment?

Much has been written about Reddit in popular media but the site is remarkably under-represented in academic research. What research there is tends to focus on usage patterns among Western users. Bergstrom (2011) focuses on the actions of a USbased Redditor who became famous for posting as an 80 -year old grandfather. 'Captain Wiggly', as he was known, was later revealed as a fraud and the site was divided over whether he was a 'troll' (a kind of online agent provocateur whose raison d'être is to inflame other users' sensibilities) or simply an interactive 'character'.

Duggan and Smith (2013) asserted that " $6 \%$ of online adults are Reddit users", while only polling a sample of 2252American users.Singer, Flock, Meinhart, Zeitfogel and Strohmeier(2014) were responsible for the creation of a longitudinal study that found that "Reddit has evolved from a small community capturing a broad topic area to a platform covering a large number of distinct subcommunities with specialized interests and topics".

However, this diversity is not reflected in research on Reddit usage in Asia, or more specifically in Indonesia, the fourth-largest country in the world. As far as the authors are aware, there is no research that focuses on Reddit usage in the country and this research seeks to fill that gap in the literature.The researchers were moved to consider what Indonesian internet users would talk about or post in a prohibited environment. Hence, the researchers developed the following research questions:

Would the research vindicate the government's decision to ban the website on the strength of the 
content Indonesians were most likely to gravitate towards (in their own dedicated subreddit)? The researcher wanted to ascertain how much 'free speech' in a prohibited environment led to posts that were incongruent with the normative social values of Indonesian society (pornography, seditious or anti-social humor, a disregard for the accepted norms such as religious values, social mores, linguistic etiquette etc.).

In a 'speakeasy' environment would the forum resemble a wild-west-freedom-for-all- style, or would it police itself as if it was not banned? Indonesian culture is saturated with loose adoption of prescribed laws; often a policeman has to ensure that adherence to the law is performed and in the absence of such officials, Indonesians often establish de facto methods of circumventing laws.

Would the community use English, or default to Bahasa Indonesia? It is not explicitly necessary to use English to post; it is just listed in the forum guidelines as preferable to use English.This could determine if the users felt that adherence to the suggested regimen was unnecessary or overly prohibitive to Indonesians wanting to speak their own language freely.

\section{LITERATURE AND METHODOLOGY}

This study used mixed-methods research. The researchers studied the 200 most popular posts of all time on the r/Indonesia subreddit in February 2019. These were ranked by Reddit according to the number of upvotes/downvotes from readers of the forum, so were self-selected by members of the in-group being researched rather than chosen/ sampled by the researcher. The ranking system is subject to Reddit's algorithm; due to the site being in dynamic flux this research was a snapshot of the top 200 at that particular moment in time (February to March 2019).

The researchers sought to ascertain whether the titles of the posts were in Bahasa Indonesia, or in English, as the site suggests they should be, or whether they were a mix of languages. This tallying system was quantitative in nature as it generated percentage results. The research was qualitative in the sense that the posts had to be coded according to the researchers' categorizations. After qualitative coding, the data could be rendered as a quantitative tally system of the number of posts that fell into single or multiple categories. Many posts fell into multiple categories based on their content. As much of the content required knowledge of the Indonesian political and social scene the research coding was conducted by an expatriate researcher and an Indonesian researcher

After 200 posts, it was evident that the data was becoming 'saturated', in that no new categories were being generated. According to Faulkner and Trotter (2017), this was deemed the point at which further research was unlikely to yield further useful insights.

\section{RESULTS AND DISCUSSION}

Users of the forum posted predominantly in English (60.5\%), with Indonesian used second most often and a mixture of languages (English and Bahasa Indonesia, Bahasa Indonesia and Javanese) used sparingly (7\%).

\section{Language Use in the Reddit Post Sample}

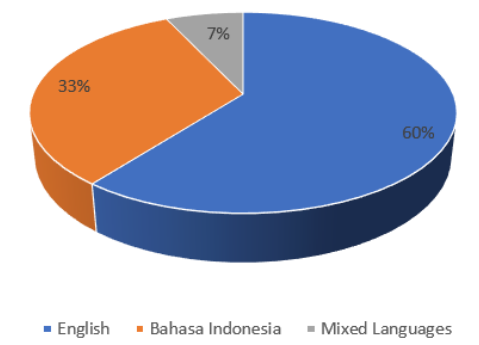

Figure 1. Languages used in the sample of Reddit posts. (Source: authors' research)

When comparing English with a combination of the other languages used English was chosen at a $3: 2$ ratio $(60 \%, 40 \%)$. This is in line with the guidelines for the posts on the sub-reddit which suggests English as the primary language.

The content was divided into 33 categories. These categories were not mutually exclusive, and many of the post were filed into multiple categories. The six most prevalent categories were Humor with 119 posts (59.5\%); Memes, 83 posts (41.5\%); Indonesian Politics, 38 posts (19\%); 
Table 2. Distribution of categories and interaction of categories in the top 200 Reddit posts. (Source: authors' research)

\begin{tabular}{|c|c|c|c|c|c|c|c|c|}
\hline $\begin{array}{l}\text { Humor } \\
\text { only: }\end{array}$ & $\begin{array}{l}\text { Humor in } \\
\text { combination } \\
\text { with: }\end{array}$ & $\begin{array}{l}\text { Num } \\
\text { ber of } \\
\text { Posts }\end{array}$ & $\begin{array}{l}\text { Meme } \\
\text { s }\end{array}$ & $\begin{array}{l}\text { Memes in } \\
\text { combinati } \\
\text { on with: }\end{array}$ & $\begin{array}{l}\text { Number } \\
\text { of Posts }\end{array}$ & $\begin{array}{l}\text { Politi } \\
\text { cs }\end{array}$ & $\begin{array}{l}\text { Politics in } \\
\text { combinatio } \\
\text { n with: }\end{array}$ & $\begin{array}{l}\text { Number } \\
\text { of Posts }\end{array}$ \\
\hline \multirow[t]{10}{*}{24} & Memes & 40 & 6 & Humor & 40 & 6 & $\begin{array}{l}\text { Humor/Me } \\
\text { mes }\end{array}$ & 16 \\
\hline & $\begin{array}{l}\text { Politics/Mem } \\
\text { es }\end{array}$ & 16 & & $\begin{array}{l}\text { Humor/Po } \\
\text { litics }\end{array}$ & 16 & & News & 5 \\
\hline & $\begin{array}{l}\text { Religion/Me } \\
\text { mes }\end{array}$ & 12 & & $\begin{array}{l}\text { Religion/ } \\
\text { Humor }\end{array}$ & 12 & & Religion & 5 \\
\hline & Food & 11 & & $\begin{array}{l}\text { Food/Hum } \\
\text { or }\end{array}$ & 6 & & Humor & 3 \\
\hline & Food/Memes & 6 & & $\begin{array}{l}\text { Religion/ } \\
\text { Humor/Fo } \\
\text { od }\end{array}$ & 1 & & $\begin{array}{l}\text { News/Reli } \\
\text { gion }\end{array}$ & 2 \\
\hline & Religion & 4 & & Food & 1 & & $\begin{array}{l}\text { News/Hu } \\
\text { mor }\end{array}$ & 1 \\
\hline & Politics & 3 & & Religion & 1 & & & \\
\hline & $\begin{array}{l}\text { Religion/Foo } \\
\text { d/Memes }\end{array}$ & 1 & & & & & & \\
\hline & $\begin{array}{l}\text { News/Politic } \\
\mathrm{s}\end{array}$ & 1 & & & & & & \\
\hline & $\begin{array}{l}\text { Religion/Foo } \\
\text { d }\end{array}$ & 1 & & & & & & \\
\hline $\begin{array}{l}\text { Religi } \\
\text { on } \\
\text { only: }\end{array}$ & $\begin{array}{l}\text { Religion in } \\
\text { combination } \\
\text { with: }\end{array}$ & $\begin{array}{l}\text { Num } \\
\text { ber of } \\
\text { Posts }\end{array}$ & $\begin{array}{l}\text { Food } \\
\text { only: }\end{array}$ & $\begin{array}{l}\text { Food in } \\
\text { combinati } \\
\text { on with: }\end{array}$ & $\begin{array}{l}\text { Number } \\
\text { of Posts }\end{array}$ & $\begin{array}{l}\text { News } \\
\text { only: }\end{array}$ & $\begin{array}{l}\text { News in } \\
\text { combinatio } \\
\text { n with: }\end{array}$ & $\begin{array}{l}\text { Number } \\
\text { of Posts }\end{array}$ \\
\hline \multirow[t]{11}{*}{--} & $\begin{array}{l}\text { Humor/Mem } \\
\text { es }\end{array}$ & 12 & 3 & Humor & 11 & 8 & Religion & 4 \\
\hline & Politics & 5 & & $\begin{array}{l}\text { Humor/M } \\
\text { emes }\end{array}$ & 6 & & $\begin{array}{l}\text { Religion/P } \\
\text { olitics }\end{array}$ & 2 \\
\hline & Humor & 4 & & $\begin{array}{l}\text { Religion/ } \\
\text { Humor }\end{array}$ & 1 & & Politics & 5 \\
\hline & News & 4 & & $\begin{array}{l}\text { Religion/ } \\
\text { Humor/M } \\
\text { emes }\end{array}$ & 1 & & $\begin{array}{l}\text { Humor/Pol } \\
\text { itics }\end{array}$ & 1 \\
\hline & $\begin{array}{l}\text { News/Politic } \\
\mathrm{s}\end{array}$ & 2 & & Memes & 1 & & & \\
\hline & Tolerance & 2 & & & & & & \\
\hline & Memes & 1 & & & & & & \\
\hline & Artwork & 1 & & & & & & \\
\hline & Photography & 1 & & & & & & \\
\hline & Food/Humor & 1 & & & & & & \\
\hline & $\begin{array}{l}\text { Food/Humor/ } \\
\text { Memes }\end{array}$ & 1 & & & & & & \\
\hline
\end{tabular}

Religion, 34 posts; (17\%); Food, 23 posts (11.5\%); and News, 20 posts $(10 \%)$. These categories and their relationships with other categories were investigated to determine the prevalence of independent or multi-categorical content (tabel 2).
The distribution of categories and category combinations can be seen in the following table:

As mentioned earlier, popularity on Reddit is roughly ascertained by upvotes (upvotes minus 
downvotes $=$ eventual score). These upvotes are referred to as 'karma'. Karma on Reddit has no intrinsic value beyond 'bragging rights' .

The 10 most popular posts (most popular=most upvotes), are from a variety of categories. The following table exemplifies the variety of content despite being a relatively small sub-reddit:

Table 3. Distribution of the top ten posts on $\mathbf{r}$ / Indonesia (Source: authors' research)

\begin{tabular}{lll}
\hline Ranking & Upvotes & Categories \\
\hline 1. & 440 & External News/Criminal \\
\hline 2. & 368 & Religion/Artwork \\
\hline 3. & 282 & Religion/Tolerance \\
\hline 4. & 266 & Food/Memes/Artwork \\
\hline 5. & 256 & $\begin{array}{l}\text { Western } \\
\text { Stereotypes/Humor/Memes }\end{array}$ \\
\hline 6. & 247 & Humor/Memes \\
\hline 7. & 238 & $\begin{array}{l}\text { Humor/Indonesian } \\
\text { Politics/Memes }\end{array}$ \\
\hline 8. & 233 & News/Indonesian Politics \\
\hline 9. & 232 & $\begin{array}{l}\text { Humor/Indonesian } \\
\text { Politics/Memes }\end{array}$ \\
\hline 10. & 232 & Food/Humor/Memes \\
\hline
\end{tabular}

It can be seen from the table that there was a large degree of cross-over of the content of the posts.

It can come as no surprise to those who have had more than a cursory glance at the internet that the medium, especially in its guise as 'Web $2.0^{\prime}$ is driven by the transmission of humorous photographs, videos, songs, pictures of cats, and various kinds of newly-evolving silliness. This is not to say that old-fashioned 'knock-knock' or 'dad' jokes are on the way out; they have a strong following on the internet as well (see r/dadjokes). Humor is obviously and famously subjective, but it is a common human trait that most people can detect attempts at humor, even if they do not fall within the parameters of their own personal tastes. This was one of the reasons that the paper was co-researched and co-written, to prevent a single voice arbitrarily ascribing humor where it was not present. Out-group stereotype-based jokesthat were obvious to the indigenous researcher may not have been immediately apparent to a foreign researcher. Some posts in the Reddit top two hundred of $r$ / Indonesia required a grounded background in
Indonesian culture and knowledge of the nuances and wordplay therein.

Humorfeatured in 59.5\% ofthepostsandreflected a wide variety of sophistication from stereotypical observations about expatriates and puns through to a cleverly-observed photograph that satisfied both a current internet trope, and evoked a familiar Indonesian context. The photograph (https://www. reddit.com/r/indonesia/comments $/ 6 \mathrm{p} 07 \mathrm{sb} /$ perfect timing/?ref=share\&ref_source=link) shows a single glass door of an office building; the other glass door has been broken. The remaining lefthand door has four letters on it: REKT, the current internet parlance for 'savagely destroyed'. It is obvious to Indonesian viewers that the rest of the door would and should have had 'ORAT' displayed on it. Its omission creates the humor; the glass door has, indeed, been savagely destroyed.

The humor is largely free of cynicism and 'darkness'. It is predominantly playful in nature and is inclined towards provoking chuckles rather than inciting hilarity. 'Edginess' that has pervaded other areas of the internet remains refreshingly unrewarded in $r /$ Indonesia. There is a wholesome nature to much of the humor, and a collective sense of understanding of what will work well, and what will not.

Image macro memes - commonly referred to simply as memes- were notable by their prevalence in the two hundred most popular posts (41.5\% of all posts). Memes, according to Knobel and Lankshear (2006) are "a popular term for describing 'catchy' and widely propagated ideas or phenomena".Hristova (2014) states "Firing up overnight, and disappearing just as quickly, memes are often allowed to run their course and fade into oblivion". They are usually take the form of a visually attention-grabbing graphic and a few lines of text above and below the image. This reflects the curtailed Millennial cultural attention span that embraces the 'TL;DR' (Too Long; Didn't Read) culture (McNeill, 2011). Memes tend to have a tight 'attention' window and can be shared virally while they are 'hot' but the typical life of a meme is short as they can capture the zeitgeist in one time period, and appear 'used-up' and 'over' the next. 
However, memes only have cultural currency while the event or phenomenon alluded to in the meme are still relevant to the in-group; they lack the cultural currency of a political scandals, or social phenomena, which can be ongoing and returned to by the users to add further reaction. Their strong presence in the top 200 posts demonstrates a tenacity, given that memes only had a short life expectancy originally.

The memes in $r /$ Indonesia are relatively harmless in these researchers' judgments. The majority are good, clean fun, while the worst would be considered 'ribbing' the reputation of politicians or celebrities who were in the limelight for their misdeeds. Comparing these memes with subreddits such as $\mathrm{r} /$ thedonald (a self-admitted right-wing fan subreddit for the $45^{\text {th }}$ American president) can only reflect favorably on the memes in $\mathrm{r} /$ Indonesia

Politics and politicians garner 'water-cooler conversations' wherever you are in the world, and Indonesia is no exception. 2017 saw a scandal involving Setya Novanto, a member of the Indonesian House of Representatives from the Golkar Party, who was in charge of overseeing the national distribution of electronic identity cards. He was alleged to have embezzled funds from the scheme to enrich himself. Due to claims of ill health and a car accident, his eventual conviction and imprisonment was delayed. This led to bemusement from the public, and online meme-makers took the opportunity to seize on the downfall of the politician, and amused themselves by creating memes as a form of schadenfreude.

Another jailed politician was widely discussed so the post ranked highly in the top 50; many people were sympathetic to the downfall of Basuki Tjahaja Purnama - popularly known as 'Ahok' - who was imprisoned in May 2017. He was convicted of blasphemy in a controversial trial that attracted international attention, and divided public perceptions of the Christian Chinese/Indonesian politician (Lamb, 2016; Harvey, 2017). While in prison, he divorced from his wife of 21 years, Veronica Tan. This was shocking for his followers, who considered him a devoted family man. Ahok was also discussed in the thirteenth-ranking post; after he was imprisoned, a highly-regarded popular singer wrote a post on Instagram that exemplified Ahok's fairness and even-handedness, traits that were admired and respected in the comments section.

Religion plays an integral role in Indonesian life and politics. Indeed, this was borne out in the analysis of the posts; religion never featured independently but was very prevalent, matching up with a host of different content such as: Humor and Memes (12 posts); Politics (5); Humor (4); News (4); Tolerance (2) News, and Politics (2); Artwork (1); Photography (1 post); Memes (1); Food, and Humor (1 post); and finally, Food, Humor and Memes (1). This demonstrates the degree to which religion permeates Indonesian society.

A belief in a monotheistic deity is the first of the five pillars of the Indonesian ideology 'Pancasila' (Kim, 1998) which is enshrined in the Indonesian national constitution. Hence, matters of a religious nature rarely exist in a purely religious vacuum; the same can be said for political maneuvering as it relies on the oxygen of public acceptance. The advocates of the majority religion, Islam, are often viewed through the prism of dominance by minority religions due to the majority religion's prevalence in everyday Indonesian life.

The center of Indonesian political life, the island of Java, was widely seen as having too much political sway on the other islands' destinies. According to Nasution (2016), "Without much preparation, Indonesia, in 2000, at a stroke replaced the previous system of centralized government and development planning with a wide range of decentralization programs. The reforms gave greater authority, political power, and financial resources directly to regencies and municipalities". This gave greater autonomy to the regions and allowed for the voicing of regional issues that were previously under-represented, such as those of minority religious interests.

Rather than promoting disharmony or religious conflict, many of the religious/political posts in $\mathrm{r} /$ Indonesia have a collaborative, cooperative voice. A post of a two-panel cartoon depicts a crowd 
of Muslims standing outside a church, with a church-goer leaving the church. In the first panel, a member of the crowd says, "this church does not have a license!". In the second panel the same member of the crowd steps up to join the churchgoer, and declares "Come on! Let's help them get a license". This reflects the wider social zeitgeist of bureaucratic intransigence in some regions when churches apply for legal licenses to open or operate.

A cooperative approach to diversity is widely praised among the commenters on the thread. This actually reflects the national slogan 'unity in diversity' (bhinneka tunggal ika), a muchvaunted element of the country's national identity. In espousing the national ethos in this way, the Reddit users are essentially toeing the line of societal expectation, even without authoritarian supervision.

It should be noted that across the main Reddit website liberal and moderate ideologies prevail; some $79 \%$ of the American Reddit population claimed that they were liberal $(41 \%)$ or moderate (38\%) (Statista, 2016). This liberal or moderate ethos is also in evidence in r/Indonesia; in the 2018 Reddit Census, 79\% declared themselves liberal, $11 \%$ moderate and only $10 \%$ conservative (Reddit Census, 2018). However, this liberalism could prove to be threatening to the government in a country that is widely regarded as becoming increasingly conservative (Varagur, 2017; Wibawa, 2018; Maulia, 2019).

Indonesia is proud of its local cuisine with good reason. Two of Indonesia's most popular dishes, rendang (coconut milk-stewed beef from west Sumatra) and nasi goreng (fried rice) were voted first and second in a worldwide CNN poll on the world's most delicious food in 2017 (Wonderful Indonesia, 2018). The treatment of food on $r /$ Indonesia reflects a national pride in local cuisine. The users of $r$ /Indonesia adopt a conversational swagger when referring to Indonesian staples such as Indomie, the most popular instant noodle brand in the country. The fourth most popular post at the time of writing was a cartoon which anthropomorphized Indomie into an anime-style female. Referring to the creation as "our godess [sic] Indomie", the post created a stir among the commenters, mostly referring to the attention to detail in the artwork. The post's continued popularity is likely due to the ubiquity of the foodstuff and the enthusiasm of its devotees.

Again, unbeknownst to the posters, they are toeing the line of nationalism and internally promoting Indonesian products when strictly speaking, they do not have to. Due to the in-group shared enjoyment of an Indonesian product, they are performing exactly as they would (and should) without the oversight of an authority source.

Indonesia is known to many in the Western world as the home of Bali, the famous beach and honeymoon island. Unfortunately, most Western exposure of Indonesia outside of Bali is due to the prevalence of natural disasters. As the archipelagic country sits upon the Pacific 'Ring of Fire', it experiences frequent volcanic eruptions, earthquakes, and tsunamis. Boxing Day (December 26) of 2004 was memorable around the world for a massive tsunami originating in the Indian Ocean which struck Indonesia, in particular the north Sumatran autonomous region of Aceh, were 170,000 people died (Roos, 2018). More recently, the volcanic mountains Gunung Merapi, Gunung Agungand Gunung Sinabung have all proved dangerous to locals due to full or partial eruptions. According to World Vision (2018), an undersea slide at Anak Krakatau (the 'child' of the infamous volcano) caused a tsunami that killed 400 people in Palu, Central Sulawesi.

Although these stories resonate in Indonesia, there is also a sense of conditioned acceptance about the repetitious nature of these disasters. Due to the frequency of these events, they lack a visceral terror for most Indonesian Redditors; unless the disaster somehow beats the terrifying statistics of 2004 it is taken with resignation as an inevitable cost of living in the country. There were eight major earthquakes in 2018, six of over 6.0 magnitude (World Vision, 2018); none of them featured on the top 200 stories of all-time.

It is quite plausible that as Redditors feel that they have no control over environmental factors 
such as earthquakes, volcanoes and tsunamis, they turn their attention towards political scandals. Since democracy is relatively new to Indonesia the democratic system is just over two decades old - outrage is regularly directed at those who have abused this new-found 'privilege' by indulging in KKN (Korupsi, Kolusi, Nepotisme - corruption, collusion and nepotism).

Hence, many of the stories in the top 200 that were adjudged to be 'news' were political in nature. Indonesians, often referred to as the orang kecil (little people) by politicians can find unity in diversity in their shared enjoyment of watching the mighty fall. The closest the forum came to pornography in the sample in a fauxhistorical photograph of a topless Balinese woman in traditional dress. Given that toplessness was part of the fabric of Balinese social life (Bali.com, n.d.), the photograph has minimal titillation value, unlike much of the content available on other websites/subreddits.

The only other allusion to nudity was in the top post (number 1 of the forum) of an Australian news story in which an Indonesian student attempted to plant a camera in a bathroom shower that he shared with female Australians, who was subsequently caught. The newspaper article focuses rather ironically on the Indonesian student's appeal for privacy (Thompson, 2018). The forum lambasted the student for making Indonesians look bad abroad. User u/esreddither said "He's a disgrace" (2018). This is in keeping with an Indonesian sense of damaged national pride, and thus normative social reactions to the story were followed, despite lacking any form of authoritarian oversight encouraging or enforcing normative behavior. This goes some way to explaining how the forum is self-policing, and this satisfies the issue raised in research question 2 .

\section{CONCLUSIONS \& DISCUSSIONS}

The results and subsequent discussion demonstrate that users of $\mathrm{r} /$ Indonesia are largely self-policing and observe social norms even in a space that could be abused and taken advantage of during its time in the 'blocked wilderness'. There is no sense of lawlessness, anarchy or sedition. Whether knowingly or unknowingly, most of the sampled posts have a 'vanilla' wholesomeness, an adherence to normative social values and an acceptance of Indonesian values and mores.

It might prove useful to the Indonesian government to reconsider banning the entire website. The sub-reddit devoted to Indonesia is largely healthy, if mildly scathing of local politics, which on the balance of things does not seem entirely unwarranted. Indonesia tends to have political scandals at an alarming rate, and it would be quite unusual for its citizens not to try to find humor in the drama.

Its users, whilst declaring themselves liberal in the majority, are notably nationalist/patriotic and appear to follow both the national ideology (Pancasila), the national motto 'unity in diversity' and the social norms of the country. They are primarily digital natives so are au fait with the latest trends and memes internationally. However, political agitation and antagonistic fomentation of government rejection arenotably lacking. The subreddit could be considered as less of a threat than any group of educated, liberal twenty-somethings in a bar or restaurant. The Indonesian government should recognize that the site is a strong tool for garnering unfettered public opinion and use it as a sounding board for policy ideas. To this end, the researchers would recommend dialogue between Reddit and the Indonesian government to facilitate greater transparency and trust in the users of the site.

This research lacks a gender division due to the anonymization of Reddit users. It could be useful for future researchers to study the input of Indonesian Redditors through the prism of gender, location and/or family income to determine whether the posts on Reddit are truly felt to represent the entire cohort, or just a vocal (textual) sub-section.

The researchers also recognize the difficulty of replicating a study that took place at a particular moment in time in a dynamic environment where rankings can change on a day-by-day basis. Due to the nature of Reddit as a live forum in flux, it is hoped that a longitudinal study could remedy this 
shortcoming.

In terms of studies of population samples it is hoped that Reddit in Indonesia as a social space can be researched further, as it is a fertile ground for anonymized responses, which may provide more truthful opinions than those in public forums due to the lack of immediate social judgment.

\section{REFERENCES}

Alfonso III, F. (2012). Redditors declare war on Gawker Media. Retrieved from https:// www.dailydot.com/news/gawker-redditbanned-adrian-chen-violentacrez/

Bali. (n. d.). Brief History of Bali and the Balinese. Retrieved from https://www.bali.com/ balinese-history.html

Bergstrom, K. (2011). Don't feed the troll: Shutting down debate about community expectations on Reddit.com. Retrieved from https://journals.uic.edu/ojs/index. $\mathrm{php} / \mathrm{fm} /$ article/view/3498/3029

Duggan, M. \& Smith, A. $6 \%$ of online adults are Reddit users. Retrieved from http://www. pewinternet.org/wp-content/uploads/ sites/9/media/Files/Reports/2013/PIP reddit_usage_2013.pdf

Esreddither. (2018). University student who filmed flatmates in the shower asks for privacy. Retrieved from http://www.reddit.com/r/ indonesia/ university-student-who-filmedflatmates-in-the-shower-asks-for-privacy20180427-p4zc1w.html

Faulkner, S. L. \& Trotter, S. P. (2017). Data Saturation. Retrieved from https://doi. org/10.1102/9781118901731.iecrn0060

Google Trends. (2018). Reddit. Retrieved from https://trends.google.com/trends/explore?d ate $=$ all \&geo $=$ ID\&q $=$ reddit

Greenberg, J. (2015). For the record: the relationship between WIRED and Reddit. Retrieved from https://www.wired.com/2015/07/ wired-conde-nast-reddit/

Harvey, A. (2017, May 9). Jakarta's Christian governor Ahok found guilty in Islam blasphemy trial. Retrieved from https:// www.abc.net.au/news/2017-05-09/ jakartas-outgoing-governor-ahok-foundguilty-in-blasphemy-trial/8509936

Hristova, S. (2014). Visual Memes as Neutralizers of Political Dissent. Retrieved from https:// www.triple-c.at/index.php/triplec/article/ view/507/541

Kim, H. J. (1998). The Changing Interpretation of Religious Freedom in Indonesia. Retrieved from https://scholar.google. co.id/scholar?hl=en\&as_sdt $=0 \% 2 \mathrm{C} 5 \& \mathrm{q}=\mathrm{T}$ he + Changing + Interpretation + of + Religiou $\mathrm{s}+$ Freedom $+\mathrm{in}+$ Indonesia\&btnG $=$

Knobel, M., \& Lankshear, C. (2006). Online Memes, Affinities, and Cultural Production. Retrieved from http://literacyandtech. pbworks.com/f/Text.pdf\#page $=209$

Lamb, K. (2016, December 12). Jakarta governor Ahok's blasphemy trial: all you need to know. Retrieved from https://www. theguardian.com/world/2016/dec/12/ jakarta-governor-ahoks-blasphemy-trialall-you-need-to-know

Lukman, E. (2014). Amid online porn crackdown, Vimeo, Reddit and Imgur are blocked in Indonesia. Retrieved from http://www. techinasia.com/online-porn-crackdownvimeo-reddit-imgur-blocked-indonesia/

McNeill Jr., R. G. (2011). Adapting Teaching to the Millennial Generation: A Case Study of a Blended/Hybrid Course. Retrieved from https://scholarworks.umass.edu/cgi/ viewcontent.cgi? article $=1747 \&$ context $=$ re fereed

Mason, J. (2018). Are VPNs legal in your country? Retrieved from https://thebestvpn.com/arevpns-legal-banned-countries/

Maulia, E. (2019). Indonesia's conservative Islam regains clout ahead of elections. Retrieved from https://asia.nikkei.com/Politics/ Indonesia-s-conservative-Islam-regainsclout-ahead-of-elections

Nave, K. (2016). Infoporn: How VPN use varies by country. Retrieved from https://www. 
wired.co.uk/article/vpn-use-worldwideprivacy-censorship

Nicol, W. (2018). What is Reddit? A beginner's guide to the front page of the internet. Retrieved from https://www.digitaltrends. com/social-media/what-is-reddit/

Nguyen, T. (2011). Anderson Cooper vs. Reddit. Retrieved fromhttps://dailycaller. com/2011/09/30/anderson-cooper-vsreddit/

Reddit Census. (2018). r/Indonesia 2018 Census. Retrieved from https://docs.google.com/forms/d/ e/1FAIpQLScncDBKI115MtQUrMi2Y OPRunQ739ffVNJiVEZKzcoXA1LIA/ viewanalytics

Redditmetics. (2019). Top Subreddits. Retrieved from http://redditmetrics.com/top

Roos, D. (2018). The 2004 Tsunami Wiped Away Towns With 'Mind-Boggling' Destruction. Retrieved from https://www.history.com/ news/deadliest-tsunami-2004-indianocean

Singer, O., Flock, F., Meinhart, C., Zeitfogel, E. \& Strohmeier, S. (2014). Evolution of Reddit: From the Front Page of the Internet to a Self-referential Community? Retrieved from https://arxiv.org/pdf/1402.1386.pdf

Statista. (2016). Distribution of Reddit users in the United States as of February 2016, by political spectrum. Retrieved from https:// www.statista.com/statistics/517259/reddit- user-distribution-usa-political-spectrum/

Thompson, A. (2018). University student who filmed flatmates in the shower asks for privacy. Retrieved from https://www.smh. com.au/national/nsw/university-studentwho-filmed-flatmates-in-the-shower-asksfor-privacy-20180427-p4zc1w.html

Top Sub-reddits. (2018, March 1). Retrieved from http://redditmetrics.com/top

Varagur, K. Indonesia's Moderate Islam is Slowly Crumbling. Retrieved from https:// foreignpolicy.com/2017/02/14/indonesiasmoderate-islam-is-slowly-crumbling/

Wibawa, T. (2018). Fatwas, niqabs and 'acceptable standards': Is conservative Islam on the rise across Indonesia? Retrieved from https:// www.abc.net.au/news/2018-09-09/arewe-seeing-a-rise-in-islamic-conservatismacross-indonesia/10173972

Wonderful Indonesia. (2018). Once Again! Indonesia's RENDANG and NASI GORENG Crowned World's Best Foods. Retrieved from https://www.indonesia. travel/gb/en/news/once-again-indonesia-srendang-and-nasi-goreng-crowned-worlds-best-foods

World Vision. (2018). 2018 Indonesia quakes and tsunamis: Facts, FAQs, and how to help. Retrieved from https://www.worldvision. org/disaster-relief-news-stories/2018indonesia-earthquake-facts 